\title{
Ibutilide protects against cardiomyocytes injury via inhibiting endoplasmic reticulum and mitochondrial stress pathways
}

\author{
Yu Wang ${ }^{1} \cdot$ Yi-Li Wang ${ }^{2} \cdot$ Xia Huang $^{2} \cdot$ Yang Yang $^{2} \cdot$ Ya-Jun Zhao ${ }^{2} \cdot$ Cheng-Xi Wei $^{1} \cdot$ \\ Ming Zhao'
}

Received: 26 March 2016 / Accepted: 7 September 2016 / Published online: 17 September 2016

(C) The Author(s) 2016. This article is published with open access at Springerlink.com

\begin{abstract}
Atrial fibrillation (AF) is a complex disease with multiple inter-relating causes culminating in rapid atrial activation and atrial structural remodeling. The contribution of endoplasmic reticulum and mitochondria stress to AF has been highlighted. As the class III antiarrhythmic agent, ibutilide are widely used to AF. This study was designed to explore whether ibutilide could treat $\mathrm{AF}$ by inhibiting endoplasmic reticulum stress pathways and mitochondria stress. The neonatal rat cardiomyocytes were isolated and exposed to $\mathrm{H}_{2} \mathrm{O}_{2}$, ibutilide was add to the culture medium $12 \mathrm{~h}$. Then the cell viability, oxidative stress levels and apoptotic rate were analyzed. In addition, endoplasmic reticulum stress related protein (GRP78, GRP94, $\mathrm{CHOP}$ ), mitochondria-dependent protein (Bax, Bcl-2) and caspase-3/9/12 were identified by real-time PCR and western blot analysis. In our results, remarkable decreased cell viability and oxidative stress levels were detected in cardiomyocytes after treating with $\mathrm{H}_{2} \mathrm{O}_{2}$. The apoptotic rate and the expression of proteins involved in mitochondrial stress and endoplasmic reticulum stress pathways increased. While ibutilide significantly inhibited these changes. These data suggested that ibutilide serves a protective role against $\mathrm{H}_{2} \mathrm{O}_{2}$-induced apoptosis of neonatal rat cardiomyocytes,
\end{abstract}

Cheng-Xi Wei

weichengxi1224@163.com

$\triangle$ Ming Zhao

langzhe73@163.com

1 Medicinal Chemistry and Pharmacology Institute, Inner Mongolia University for the Nationalities, No. 22 Holin He Street, Tongliao, Inner Mongolia 028002,

People's Republic of China

2 Affiliated Hospital of Inner Mongolia University for Nationalities, No. 1472 Holin He Street, Tongliao, Inner Mongolia 028002, People's Republic of China and the mechanism is related to suppression of mitochondrial stress and endoplasmic reticulum stress.

Keywords Ibutilide · Atial fibrillation · Oxidative stress · Endoplasmic reticulum stress $\cdot$ Mitochondrial stress

\section{Introduction}

Atrial fibrillation (AF) is the most serious cardiovascular disease in the world [1]. Because of aging of the population and improved survival of patients with other cardiovascular diseases, the prevalence of $\mathrm{AF}$ is increasing during the past few decades. In United States, the population of AF is increasing, from 2.3 million patients currently to 5.6 million by the year 2050 [2]. AF and its complication, such as palpitation, drop of cardiac output, heart failure and so on, threaten people health and increase the risk of stroke in patients [3]. The pathophysiology of AF is complex. Accumulating evidence has implicated a potential role of reactive oxygen species (ROS) production which leads to oxidative stress and apoptosis in pathogenesis of AF [4]. During the injury, mitochondria and endoplasmic reticulum (ER) play important roles [5]. Production of ROS has been linked to ER stress and the unfolded protein response (UPR), ROS plays a critical role in many cellular processes and can be produced in the cytosol and several organelles, including the ER and mitochondria [6]. However, their relationship in neonatal rat cardiomyocytes is not clear.

Many treatments have been used in AF. Catheter radiofrequency ablation has been the most widely used and the most effective method to modify the substrate of AF. But this method is suitable for use in certain patient groups [7]. Chemical drugs are less invasive, more cost-effective, and, unlike catheter radiofrequency ablation, it does not require 
sedation [8]. Common drugs used for treatment AF contain ibutilide, propafenone, dofetilide and so on [9]. Ibutilide is class III antiarrhythmic drug. It was approved on December 28, 1995 by the Food and Drug Administration. Due to ibutilide extensive first-pass metabolism, it is available only for intravenous. Ibutilide can prolong repolarization time, action potential duration, and refractory period of ventricular and atrial myocardium through its action as a potassium channel blocker, affecting the rapid component of the cardiac delayed rectifier potassium current [10]. However, the molecular mechanisms of ibutilide protective effects are still not fully clarified.

To determine the mechanism of ibutilide on protect cardiomyocytes, the neonatal rat cardiomyocytes were isolated and cultured. The model in vitro of cardiomyocytes injury by neonatal rat cardiomyocytes under $\mathrm{H}_{2} \mathrm{O}_{2}$ treatment was created. Then the existence of mitochondrial and ER stress pathways in $\mathrm{H}_{2} \mathrm{O}_{2}$-induced neonatal rat cardiomyocytes apoptosis and the protection of ibutilide were confirmed.

\section{Materials and methods}

\section{Materials}

Super M-MLV reverse transcriptase was purchased from BioTeke. RNA simple total RNA Kit was acquired from TIANGEN (Beijing, China). Ibutilide and $\mathrm{H}_{2} \mathrm{O}_{2}$ were obtained from Sigma (American). Terminal deoxynucleotidyl transferase-mediated dUTP nick end-labeling (TUNEL) assay kit was purchased from Beyotime Biotechnology (ShangHai, China).

\section{Cell culture}

Primary cultures of neonatal rat cardiomyocytes were obtained as described previously [11]. All experiments in this research were performed in accordance with the Guidelines of Animal Experiments from the Committee of Medical Ethics, National Health Department of China (1998). The cardiomyocytes were maintained in DMEM supplemented with $10 \%$ FBS (fetal bovine serum) and $1 \%$ penicillin and streptomycin under an atmosphere of $95 \%$ air and $5 \% \mathrm{CO}_{2}$ at $37{ }^{\circ} \mathrm{C}$. The medium was replaced every 3 days and cells were subcultured or subjected to experimental procedures at an amount to achieve 70-80\% confluency. $\mathrm{H}_{2} \mathrm{O}_{2}$ induced cytotoxicity at this concentration [12]. Ibutilide was present in the treatment group.

\section{Cell viability assay}

Cytotoxicity of neonatal rat cardiomyocytes was tested by the a colorimetric assay using 3-(4,5)-dimethylthiahiazo (-z-yl)-3, 5-di-phenytetrazoliumromide (MTT) (SigmaAldrich). Cells were seeded into 96-well plated and exposed to DMEM or $\mathrm{H}_{2} \mathrm{O}_{2}$ within/without ibutilide. Experiments were done during the exponential phase of cell growth.

\section{Measurement of glutathione peroxidase (GSH-px), MDA and SOD activity in cardiomyocytes}

The cellular activities of GSH-px, MDA and SOD were measured commercial assay kits according to the manufacturers' instructions. Then they were determined by commercially available enzyme-linked immunosorbent assays (ELISAs). All samples were assayed at three times.

\section{TUNEL staining}

DNA fragmentation of apoptotic cells was detected by TUNEL staining following the manufacturer's instructions. After the cardiomyocytes were cultured for $24 \mathrm{~h}$, the cells were fixed by $4 \%$ paraformaldehyde solution for $30 \mathrm{~min}$. Then $0.3 \% \mathrm{H}_{2} \mathrm{O}_{2}$ was used for block endogenous peroxidase activity in cells. Last TUNEL reaction was used to incubate cells. The results were detected by microscopy.

\section{Real-time PCR}

The RNA of cardiomyocytes was isolated by RNA extraction kit (TIANGEN, Beijing, China), and then the RNA was transcribed. The obtained cDNA was used for realtime PCR.

The primers of GRP78, GRP94, GAPDH gene fragments were designed following:

\section{GRP78-F: 5' GATAATCAGCCCACCGTAA 3' GRP78-R: 5' TTGTTTCCTGTCCCTTTGT 3' GRP94-F: 5' GATGTGGATGGCACGGTAG3' GRP94-R: 5' GTTCCCTTATTTGTGATGCA 3' GAPDH F: 5' CGGCAAGTTCAACGGCACAG 3' GAPDH R: 5' CGCCAGTAGACTCCACGACAT 3'}

Amplification was performed in duplicate on FTC-3000 Real-Time PCR system thermocycler using SYBR Green PCR Master Mix (TIANGEN, Beijing, China). The reaction condition was s $95{ }^{\circ} \mathrm{C}$ for $15 \mathrm{~min}$ and following 40 cycles: denaturation $\left(95^{\circ} \mathrm{C}\right.$ for $\left.10 \mathrm{~s}\right)$, annealing and elongation $\left(60^{\circ} \mathrm{C}\right.$ for $\left.60 \mathrm{~s}\right)$. The relative mRNA expression level of the gene was normalized to the level of GAPDH in the same sample.

\section{Western blot analysis}

Western blot was performed as described previously [13]. The primary antibodies contain anti-caspase-3 (1:500), 
anti-caspase-9 (1:500), anti-caspase-12 (1:500) (Bioss), anti-CHOP (1:1000), anti-Bcl-2 (1:1000) (Wanleibio), and anti-GRP78 (1:400), anti-GRP94 (1:400), anti-Bax (1:400) (Boster).

\section{Statistical analysis}

All values were expressed as mean \pm SEM. Multi-group comparisons of the means were carried out by matched $t$ test using SPSS 11.5.

\section{Results}

\section{Ibutilide improved the cell viability of $\mathrm{H}_{2} \mathrm{O}_{2}$-induced neonatal rat cardiomyocytes}

After different concentrations $\left(10^{-8}\right.$ to $\left.10^{-3} \mathrm{~mol} / \mathrm{L}\right)$ of ibutilide-pretreated neonatal rat cardiomyocytes about $4 \mathrm{~h}$, cell viability was detected using MTT. The results showed that the effect of ibutilide on neonatal rat cardiomyocytes emerged bi-directional with the concentration increase of ibutilide. Final concentration below $10^{-8}$ to $10^{-3} \mathrm{~mol} / \mathrm{L}$ ibutilide caused little effects on cell proliferation. While the dose of ibutilide up $10^{-4} \mathrm{~mol} / \mathrm{L}$ enhanced cytotoxicity (Fig. 1a). Then effects of ibutilide $\left(10^{-6} \mathrm{~mol} / \mathrm{L}\right)$ on $\mathrm{H}_{2} \mathrm{O}_{2}$ induced neonatal rat cardiomyocytes injury were analyzed by MTT. As shown in Fig. 1b, compared with control, the cell proliferation was markedly inhibited after $\mathrm{H}_{2} \mathrm{O}_{2}$ treatment, which was significantly improved by ibutilide.

\section{Ibutilide reduces the levels of MDA and increases the levels of SOD and GSH-px}

Physiological redox signaling is the role of reactive oxygen species (ROS) in intra- and intercellular communication [14]. When there is significant uncontrolled generation of ROS that overwhelm endogenous anti-oxidant capabilities, oxidative stress occurs; AF is associated with oxidative stress [15]. Cardiomyocytes were evaluated by ELISA. As an indicator of lipid peroxidation, the levels of MDA and SOD were analyzed (Fig. 2a, b). The levels of MDA were found to be higher in model group compared to control group, treatment with ibutilide significantly decreased the MDA levels. The levels of SOD were increased after treatment with ibutilide. The levels of GSH-px showed a significant reduction in model group compared with control group, while ibutilide increased the levels of GSH-px (Fig. 2c).

\section{Significant decreases apoptosis in the $\mathrm{H}_{2} \mathrm{O}_{2}$-treated cardiomyocytes after using ibutilide}

Apoptosis plays an important role in AF [16]. To evaluate the effect of ibutilide on cardiomyocytes, the cells were treated by $\mathrm{H}_{2} \mathrm{O}_{2}$ with or without ibutilide and measurement of cell apoptosis using TUNEL analysis. Significant amounts of TUNEL-positive cells were observed in the $\mathrm{H}_{2} \mathrm{O}_{2}$-treated cardiomyocytes compared to the control cardiomyocytes. While the number of TUNEL-positive cells were decreased after dealing with ibutilide (Fig. 3).

Apoptosis along with the activation of caspases was found in the myocardium of cardiomyopathy [17]. To confirm whether caspases were involved in the $\mathrm{H}_{2} \mathrm{O}_{2}$-induced apoptosis and the effect of ibutilide on the apoptosis, we tested the expression of Caspase-3, Caspase- 9 and Caspase-12. The higher caspase activity was detected in the $\mathrm{H}_{2} \mathrm{O}_{2}$-treated cardiomyocytes when compared to the controls, while ibutilide inhibited caspase activity (Fig. 4).

\section{Ibutilide attenuated the apoptosis through mitochondria-dependent pathway in neonatal rat cardiomyocytes}

Mitochondria-dependent pathway of apoptosis is regulated by Bcl-2 family members, such as pro-apoptotic
Fig. 1 Effect of ibutilide on cell viability by MTT assay. a, $\mathbf{b}$ Effect of ibutilide on cardiomyocytes or $\mathrm{H}_{2} \mathrm{O}_{2}$-induced cardiomyocytes injury. All data are shown as mean \pm SEM. $\# \# p<0.005$ vs. Other ibulitide treatment group, $* * * p<0.001$ vs. $\mathrm{H}_{2} \mathrm{O}_{2}$ group, $n=6$

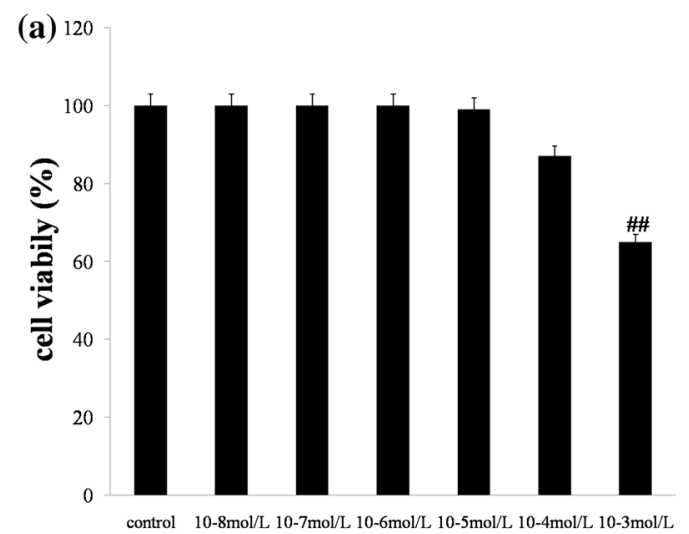

(b) 120

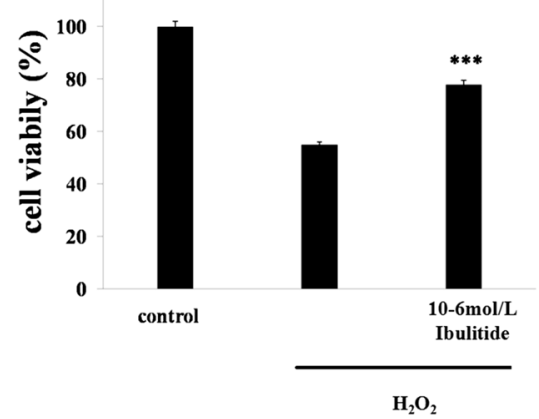


Fig. 2 Ibutilide prevents $\mathrm{H}_{2} \mathrm{O}_{2}$-induced oxidative stress. a-c ELISA examines the level of MDA, SOD, and GSH-px. All data are shown as mean \pm SEM. $* * * p<0.001$, $n=3$
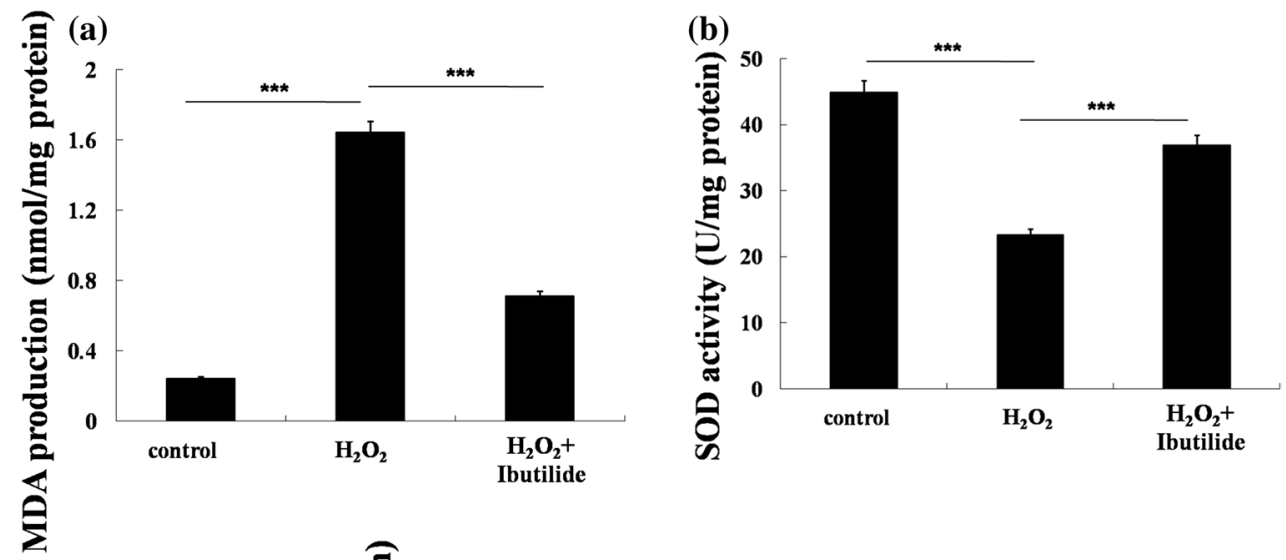

protein Bax and anti-apoptotic protein Bcl-2 which are important for the caspase activation [18]. To confirm whether mitochondria-dependent pathway related with $\mathrm{H}_{2} \mathrm{O}_{2}$ induced apoptosis, we tested the expression of Bax and Bcl-2. In our study, the expression level of proapoptotic protein Bax (Fig. 5) in model group was significantly higher than in the control and treatment group, while anti-apoptotic protein Bcl-2 (Fig. 5) in model group did not.

\section{Ibutilide attenuated the apoptosis}

through ER-dependent pathway in neonatal rat cardiomyocytes

ER stress-mediated apoptosis was also analyzed. ER is initiated by the GRP78 and GRP94 [19]. ER stress-associated genes (grp78, grp94) were analyzed by real-time PCR, and the level expressions of these proteins were evaluated by western blot. We have demonstrated grp78 or grp94 in model group were higher than control group and treatment group (Fig. 6a, c). The results of western blot were same with real-time PCR (Fig. 6b, d).

CHOP related with ER stress [20]. We tested the expression of CHOP. Ibutilide reduced ER stress as indicated decreased level of CHOP (Fig. 7).

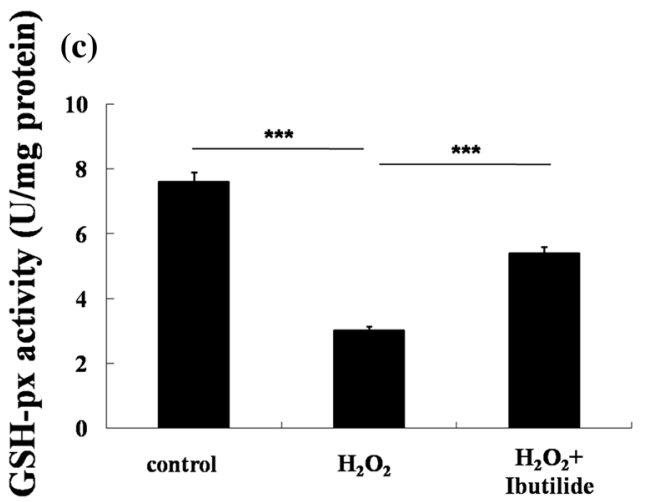

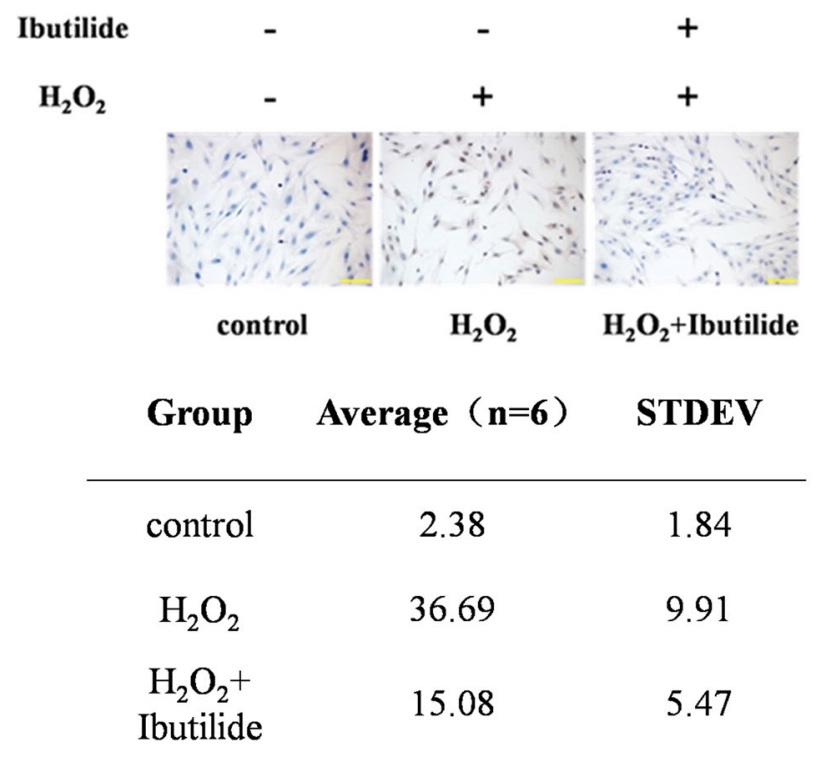

Fig. 3 Apoptosis of cardiomyocytes was detected by TUNEL

\section{Discussion}

Atrial fibrillation is responsible for a significant health care burden due to its high and growing prevalence, incidence 
Fig. 4 The expressions of Caspases were decreased by ibutilide. a-c Western blot analyze the expression of Caspase-3/9/12. All data are shown as mean \pm SEM. $* * p<0.05$, $n=3 ; * * *<0.001, n=3$ (a) $17 \mathrm{kDa}$

$43 \mathrm{kDa}$

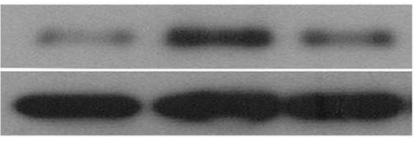

control $\quad \mathrm{H}_{2} \mathbf{O}_{2} \quad \mathrm{H}_{2} \mathrm{O}_{2}+$ Ibutilide $\star * *$

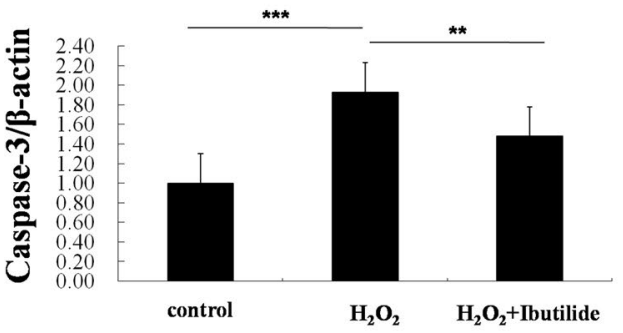

(b)
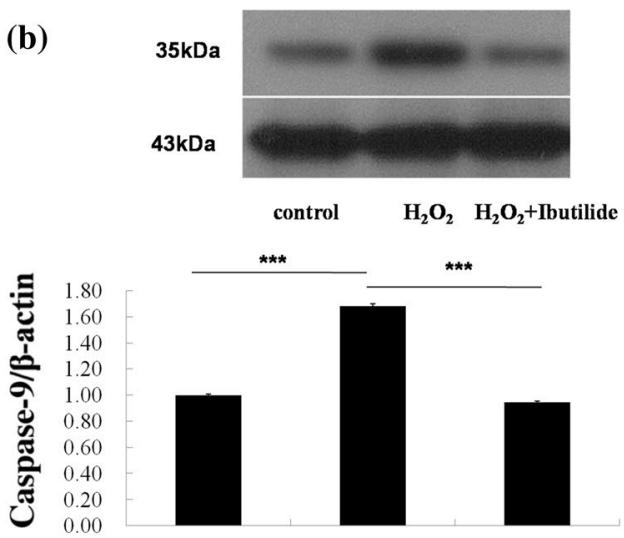

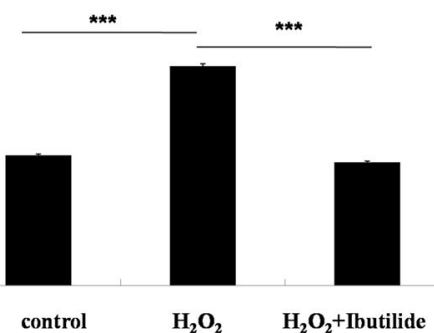

(c)

c) $46 \mathrm{kDa}$

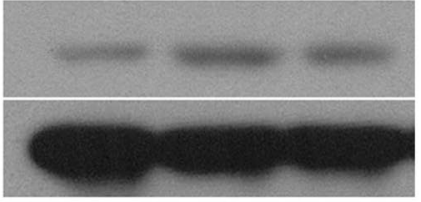

43kDa

control $\quad \mathrm{H}_{2} \mathrm{O}_{2} \quad \mathrm{H}_{2} \mathrm{O}_{2}+$ Ibutilide

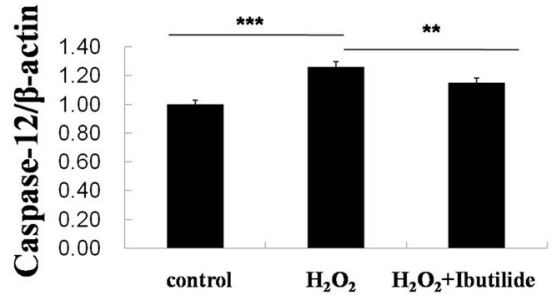

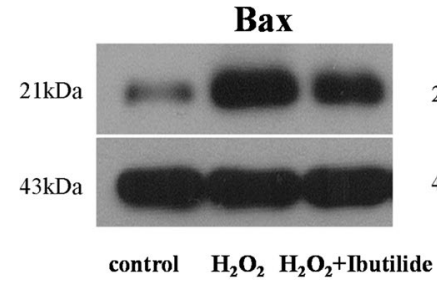
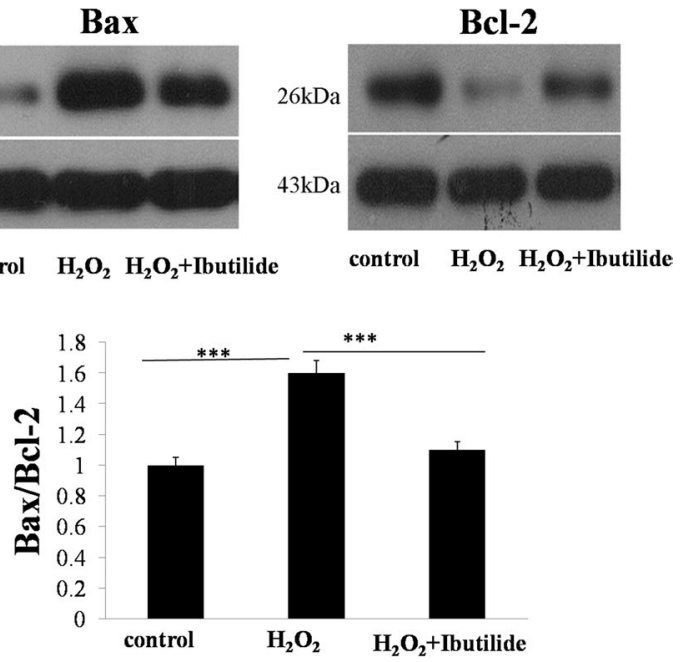

Fig. 5 Western blot analyzed the expression of Bax, Bcl-2. All data are shown as mean \pm SEM. $* * * p<0.001, n=3$

and potentially life-threatening complications [21]. The ability of ibutilide-treated atrial fibrillation has been widely acknowledged and is summarized [22]. In our study, we provide an evidence of potential therapeutic value of ibutilide-inhibited oxidative stress and apoptosis in neonatal rat cardiomyocytes subjected to $\mathrm{H}_{2} \mathrm{O}_{2}$ injury. The mechanisms of protection effects may be related with mitochondrial stress pathway and ER stress pathway.

Oxidative stress plays an important role in atrial fibrillation [23]. In cardiomyocytes, increased ROS has been found to be related with AF [24]. The increased level of ROS results in damage to proteins, lipids and DNA by augmenting cytokine production from activated inflammatory cells. ROS is involved in cardiac structural and electrical remodeling, all of which increase susceptibility to AF [23]. Our experiments determined the relative contribution of ibutilide to $\mathrm{H}_{2} \mathrm{O}_{2}$-stimulated cardiomyocytes. From the results, ibutilide resulted in a significant increase in MDA or SOD and decrease in GSH.

Apoptosis plays an important role in the pathogenesis of AF [25]. Some researchers have studied that cardiomyocyte apoptosis is related to oxidative stress [26]. In the present study, cardiomyocyte apoptosis was detected by TUNEL. Our results suggested that ibulitide could significantly reduce $\mathrm{H}_{2} \mathrm{O}_{2}$-induced apoptosis. Ibulitide also decreased the expression levels of rate of caspases.

The signal pathways through ibutilide exerted their effects that were analyzed. Mitochondrial stress pathway 
Fig. 6 Ibutilide increased the expression of GRP78 and GRP94. a, c The mRNA were examined by qPCR. b, d The protein expressions were analyzed by WB. All data are shown as mean \pm SEM. ${ }^{*} p<0.1$ or $\# p<0.1, n=3$; ** $p<0.05$ or \#\#p $<0.05, n=3$; $* * * p<0.001$ or $\# \# \# p<0.001$, $n=3$ (a)

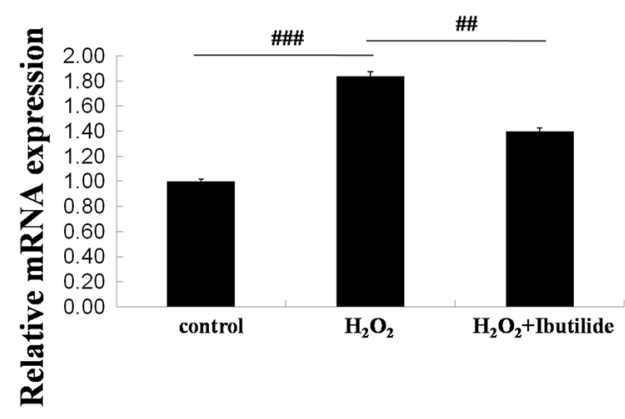

(c)

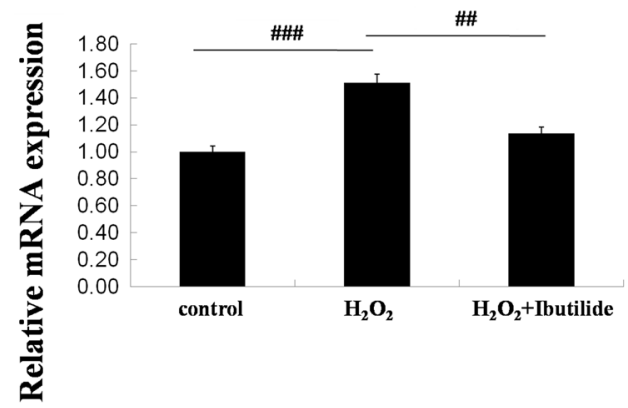

(b) $78 \mathrm{kDa}$
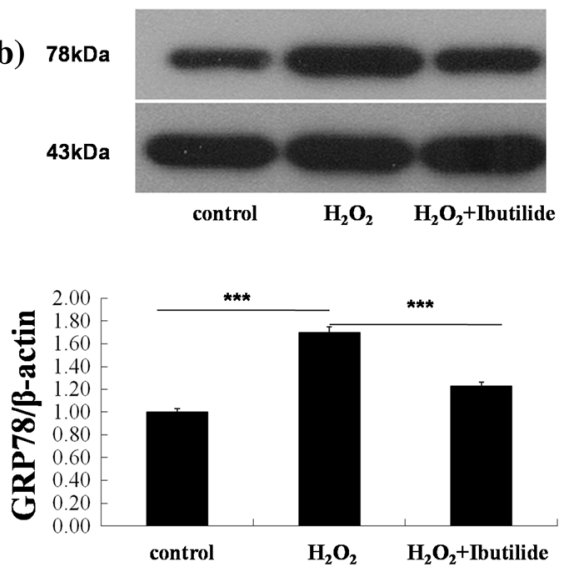

(d)
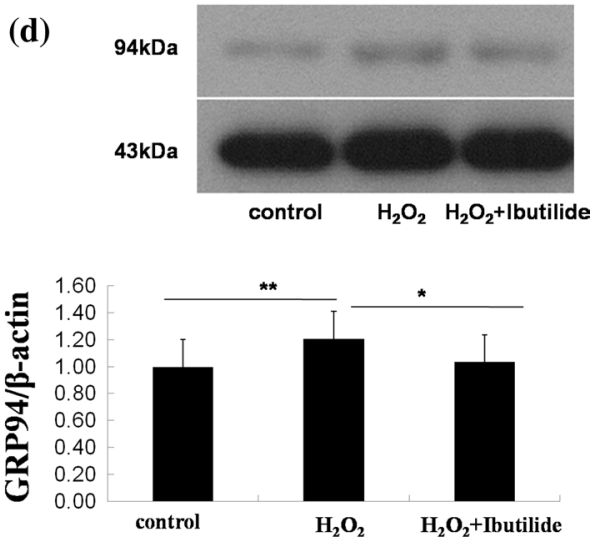

$30 \mathrm{kDa}$

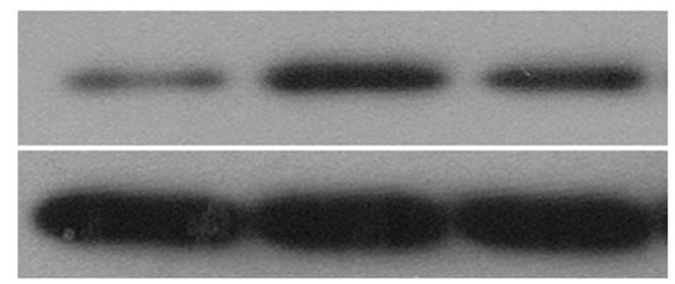

$43 \mathrm{kDa}$

control

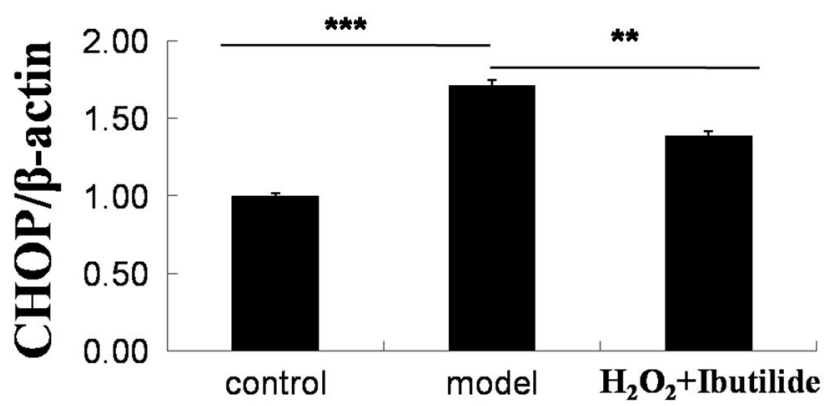

Fig. 7 The expression of CHOP decreased by ibutilide. All data are shown as mean \pm SEM. ${ }^{*} p<0.1, n=3$; $* * p<0.05, n=3$; $* * * p<0.001$

was researched. The mitochondria-dependent pathway for apoptosis is governed by Bcl-2 family proteins, such as Bax and Bcl-2 [27]. In our study, the ratio of Bax/Bcl-2 was analyzed by western blot. The increase in ratio of Bax/ Bcl-2 in $\mathrm{H}_{2} \mathrm{O}_{2}$-induced neonatal rat cardiomyocytes indicated that the cells had undergone apoptosis by a mitochondria-dependent pathway, while these parameters decreased in the group treated with ibutilide. These results suggested that the ability of ibutilide to attenuated oxidative stress is partly by inhibiting the mitochondrial-related apoptosis.

Endoplasmic reticulum (ER) has been linked to many diseases, including AF. The accumulation of misfolded protein disrupts ER and leads to the activation of the classic coping mechanism termed the unfolded protein response [28]. This response is initiated by the GRP78 or GRP94. To investigate whether ibutilide would relieve ER damage, we examined grp78 and grp94 gene by real-time PCR and these proteins expression by western blot. From these results, we demonstrated a dose-related decrease in the mRNA expression of grp78 and grp94 after treated with ibutilide. These results suggested that ER stress could be relieved in $\mathrm{H}_{2} \mathrm{O}_{2}$-induced cardiomyocytes after treating with ibutilide. ER stress occurs for recover ER homeostasis of cell survival at a short time, while prolonged ER stress would activate apoptosis [29]. CHOP related to ER stress 


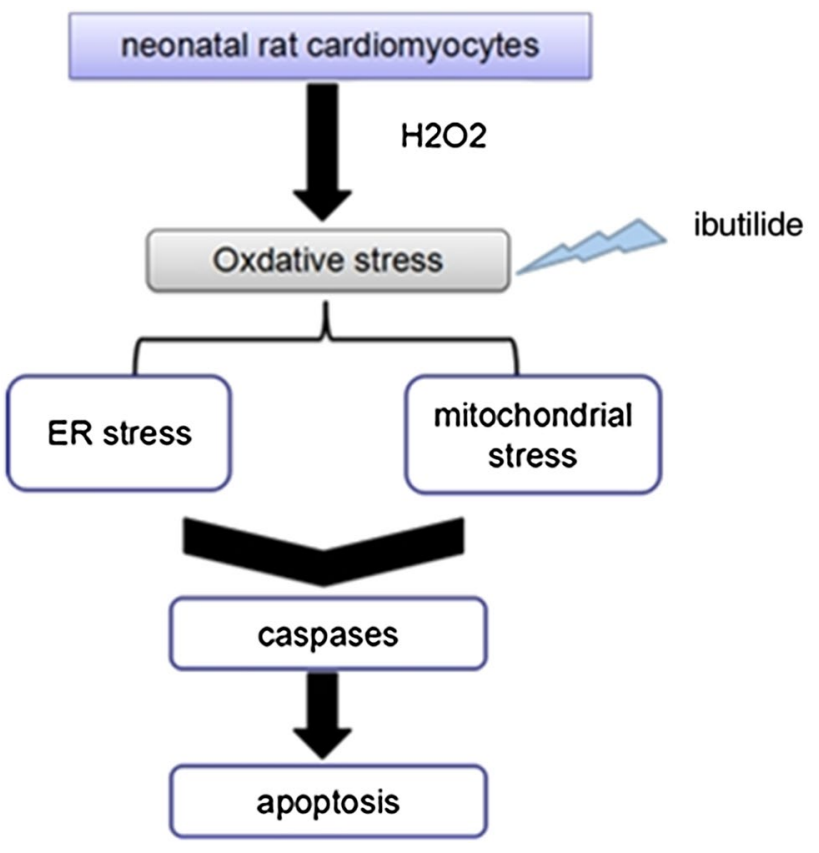

Fig. 8 Schematic diagram of the signal pathways related with $\mathrm{H}_{2} \mathrm{O}_{2}$ induced apoptosis in neonatal rat cardiomyocytes

induces apoptosis [20]. Our results showed that the expression of CHOP was decreased after treated ibutilide.

In conclusions, we provided in vitro evidence that ibutilide could protect $\mathrm{H}_{2} \mathrm{O}_{2}$-inducted oxidative stress and apoptosis, the mechanisms related with mitochondria-dependent pathways and ER stress-dependent pathways (Fig. 8).

Acknowledgments This work was supported by the National Natural Science Foundation of China (No. 81360587), Dr. Science research Start up funds of Inner Mongolia University for Nationalities (No. BS345) and the Mongolian medicine systems biology science and technology innovation team plan of Inner Mongolia.

\section{Compliance with ethical standards}

Conflict of interest The authors declare no conflict of interest.

Open Access This article is distributed under the terms of the Creative Commons Attribution 4.0 International License (http://creativecommons.org/licenses/by/4.0/), which permits unrestricted use, distribution, and reproduction in any medium, provided you give appropriate credit to the original author(s) and the source, provide a link to the Creative Commons license, and indicate if changes were made.

\section{References}

1. Matsuda H, Parwani AS, Attanasio P, Huemer M, Wutzler A, Blaschke F, Haverkamp W, Boldt LH (2015) Atrial rhythm influences catheter tissue contact during radiofrequency catheter ablation of atrial fibrillation: comparison of contact force between sinus rhythm and atrial fibrillation. Heart Vessels. doi:10.1007/ s00380-015-0763-0

2. Kataoka N, Nishida K, Kinoshita K, Sakamoto T, Nakatani Y, Tsujino Y, Mizumaki K, Inoue H, Kinugawa K (2016) Effect of irbesartan on development of atrial fibrosis and atrial fibrillation in a canine atrial tachycardia model with left ventricular dysfunction, association with p53. Heart Vessels. doi:10.1007/ s00380-016-0853-7

3. Camm AJ, Lip GYD, Caterina R, Savelieva I, Atar D, Hohnloser SH, Hindricks G, Kirchhof P (2012) ESC Committee for Practice Guidelines-CPG; Document Reviewers. 2012 focused update of the ESC Guidelines for the management of atrial fibrillation: an update of the 2010 ESC Guidelines for the management of atrial fibrillation-developed with the special contribution of the European Heart Rhythm Association. Europace 14:1385-1413

4. Youn JY, Zhang J, Zhang Y, Chen H, Liu D, Ping P, Weiss JN, Cai H (2013) Oxidative stress in atrial fibrillation: an emerging role of NADPH oxidase. J Mol Cell Cardiol 62:72-79

5. Yu W, Sheng M, Xu R, Yu J, Cui K, Tong J, Shi L, Ren H, Du H (2013) Berberine protects human renal proximal tubular cells from hypoxia/reoxygenation injury via inhibiting endoplasmic reticulum and mitochondrial stress pathways. J Transl Med $11: 24$

6. Cao SS, Kaufman RJ (2014) Endoplasmic reticulum stress and oxidative stress in cell fate decision and human disease. Antioxid Redox Signal 21(3):396-413

7. Parkash R, Tang AS, Sapp JL, Wells AG (2011) Approach to the catheter ablation technique of paroxysmal and persistent atrial fibrillation: a meta-analysis of the randomized controlled trials. J Cardiovasc Electrophysiol 22:729-738

8. Ma F, Takanari H, Masuda K, Morishima M, Ono K (2016) Erratum to: short- and long-term inhibition of cardiac inward-rectifier potassium channel current by an antiarrhythmic drug bepridil. Heart Vessels 31:1185

9. Kondo T, Miake J, Kato M, Ogura K, Iitsuka K, Yamamoto K (2015) Impact of postprocedural antiarrhythmic drug therapy with bepridil on maintaining sinus rhythm after catheter ablation for persistent atrial fibrillation. J Cardiol. doi:10.1016/j. jjcc.2015.09.012

10. Lüker J, Sultan A, Sehner S, Hoffmann B, Servatius H, Willems S, Steven D (2015) Use of antiarrhythmic drugs during ablation of persistent atrial fibrillation: observations from a large singlecentre cohort. Heart Vessels. doi:10.1007/s00380-015-0771-0

11. Wang X, Yuan B, Dong W, Yang B, Yang Y, Lin X, Gong G (2015) Humid heat exposure induced oxidative stress and apoptosis in cardiomyocytes through the angiotensin II signaling pathway. Heart Vessels 30:396-405

12. Zhao SH, Gao HQ, Ji X, Wang Y, Liu XJ, You BA, Cui XP, Qiu $J$ (2013) Effect of ouabain on myocardial ultrastructure and cytoskeleton during the development of ventricular hypertrophy. Heart Vessels 28(1):101-113

13. Wang Y, Gong GH, Zhou W, Zhang B, Bao SY, Wei CX, Yue JJ, Zhang YF (2014) Analysis on the interaction domain of VirG and Apyrase by pull-down assay. Molecules 19:18090-18101

14. Sena LA, Chandel NS (2012) Physiological roles of mitochondrial reactive oxygen species. Mol Cell 48:158-167

15. Stamboul K, Lorin J, Lorgis L, Guenancia C, Beer JC, Touzery C, Rochette L, Vergely C, Cottin Y, Zeller M (2015) Atrial fibrillation is associated with a marker of endothelial function and oxidative stress in patients with acute myocardial infarction. PLoS One 10:e131439

16. Nazari-Jahantigh M, Wei Y, Schober A (2012) The role of microRNAs in arterial remodelling. Thromb Haemost 107:611-618

17. Wan C, Chen Y, Yin P, Han D, Xu X, He S, Liu M, Hou X, Liu F, $\mathrm{Xu} J$ (2016) Transport stress induces apoptosis in rat myocardial 
tissue via activation of the mitogen-activated protein kinase signaling pathways. Heart Vessels 31:212-221

18. Beroukhim R, Mermel CH, Porter D, Wei G, Raychaudhuri S, Donovan J, Barretina J, Boehm JS, Dobson J, Urashima M, Mc Henry KT, Pinchback RM, Ligon AH, Cho YJ, Haery L, Greulich H, Reich M, Winckler W, Lawrence MS, Weir BA, Tanaka KE, Chiang DY, Bass AJ, Loo A, Hoffman C, Prensner J, Liefeld T, Gao Q, Yecies D, Signoretti S, Maher E, Kaye FJ, Sasaki H, Tepper JE, Fletcher JA, Tabernero J, Baselga J, Tsao MS, Demichelis F, Rubin MA, Janne PA, Daly MJ, Nucera C, Levine RL, Ebert BL, Gabriel S, Rustgi AK, Antonescu CR, Ladanyi M, Letai A, Garraway LA, Loda M, Beer DG, True LD, Okamoto A, Pomeroy SL, Singer S, Golub TR, Lander ES, Getz G, Sellers WR, Meyerson M (2010) The landscape of somatic copy-number alteration across human cancers. Nature 463:899-905

19. Lee JH, Kwon EJ, Kim DH (2013) Calumenin has a role in the alleviation of ER stress in neonatal rat cardiomyocytes. Biochem Biophys Res Commun 439(3):327-332

20. Zhang J, Li Y, Jiang S, Yu H, An W (2014) Enhanced endoplasmic reticulum SERCA activity by overexpression of hepatic stimulator substance gene prevents hepatic cells from ER stress induced apoptosis. Am J Physiol Cell Physiol 306:C279-C290

21. Pisters R, Nieuwlaat R, Prins MH, Le Heuzey JY, Maggioni AP, Camm AJ, Crijns HJ, Investigators Euro Heart Survey (2012) Clinical correlates of immediate success and outcome at 1-year follow-up of real-world cardioversion of atrial fibrillation: the Euro Heart Survey. Europace 14:666-674

22. Singh SM, D'Avila A, Kim YH, Aryana A, Mangrum JM, Michaud GF, Dukkipati SR, Callans DJ, Barrett CD, BerasJovine MR, Reddy VY (2012) The modified ablation guided by ibutilide use in chronic atrial fibrillation (MAGIC-AF) study: clinical background and study design. J Cardiovasc Electrophysiol 23:352-358

23. Okada A, Kashima Y, Tomita T, Takeuchi T, Aizawa K, Takahashi M, Ikeda U (2016) Characterization of cardiac oxidative stress levels in patients with atrial fibrillation. Heart Vessels 31(1):80-87

24. Chang JP, Chen MC, Liu WH, Yang CH, Chen CJ, Chen YL, Pan KL, Tsai TH, Chang HW (2011) Atrial myocardial nox2 containing NADPH oxidase activity contribution to oxidative stress in mitral regurgitation: potential mechanism for atrial remodeling. Cardiovasc Pathol 20:99-106

25. Abbate A, Narula J (2012) Role of apoptosis in adverse ventricular remodeling. Heart Fail Clin 8:79-86

26. Ibe W, Saraste A, Lindemann S, Bruder S, Buerke M, Darius H, Pulkki K, Voipio-Pulkki LM (2007) Cardiomyocyte apoptosis is related to left ventricular dysfunction and remodelling in dilated cardiomyopathy, but is not affected by growth hormone treatment. Eur J Heart Fail 9:160-167

27. Hong SH, Jang HH, Lee SR, Lee KH, Woo JS, Kim JB, Kim WS, Min BI, Cho KH, Kim KS, Cheng X, Kim W (2015) Impact of lysophosphatidylcholine on survival and function of UEA$1(+)$ acLDL(+) endothelial progenitor cells in patients with coronary artery disease. Heart Vessels 30:115-125

28. Dicks N, Gutierrez K, Michalak M, Bordignon V, Agellon LB (2015) Endoplasmic reticulum stress, genome damage, and cancer. Front Oncol 5:11

29. Li X, Wang Y, Wang H, Huang C, Huang Y, Li J (2015) Endoplasmic reticulum stress is the crossroads of autophagy, inflammation, and apoptosis signaling pathways and participates in liver fibrosis. Inflamm Res 64:1-7 